\title{
A New Experimental Approach for Hydraulic Fracturing Fluid Damage of Ultradeep Tight Gas Formation
}

\author{
Hui Li $\mathbb{D}^{1},{ }^{1}$ Zhiliang Liu, ${ }^{2}$ Ninghong Jia $\left({ }^{3}{ }^{3}\right.$ Xu Chen, ${ }^{3}$ Jing Yang, ${ }^{4}$ Lele Cao, ${ }^{1}$ and Ben Li ${ }^{1}$ \\ ${ }^{1}$ China University of Petroleum, Beijing, China \\ ${ }^{2}$ Research Institute of Exploration and Development, PetroChina Tarim Oilfield Company, Xinjiang, Korla, China \\ ${ }^{3}$ PetroChina Research Institute of Petroleum Exploration \& Development, Beijing, China \\ ${ }^{4}$ Northeast Petroleum University, Daqing, China
}

Correspondence should be addressed to Hui Li; 20234914@qq.com and Ninghong Jia; 1048019929@qq.com

Received 26 November 2020; Revised 28 January 2021; Accepted 9 February 2021; Published 25 February 2021

Academic Editor: Zhongwei Wu

Copyright (c) $2021 \mathrm{Hui}$ Li et al. This is an open access article distributed under the Creative Commons Attribution License, which permits unrestricted use, distribution, and reproduction in any medium, provided the original work is properly cited.

\begin{abstract}
The unconventional resources from an ultradeep tight gas reservoir have received significant attention in recent decades. Hydraulic fracturing is the main method for tight gas reservoir development because of its extremely low permeability and porosity. During hydraulic fracturing, high hydraulic fracturing fluid (HFF) that invaded the zone near the fracture face may reduce gas relative permeability significantly and impede gas production. The sources of this damage can be the high capillary pressure (HCP) and the presence of water-sensitive clays (PWC). For tight rock, it is usually infeasible to identify the primary damage mechanism using the traditional steady-state measurement method due to long measurement time and gauge accuracy. In this paper, we present a new experimental approach to identify the primary mechanism of the fracture face damage (FFD) through the application of the pressure transmission method and pressure decay method. Both rock matrix and naturally fractured tight samples (depth 18,000 ft, Tarim field, China) were tested. The experimental results showed that the average high capillary pressure damage indexes $\left(D_{\mathrm{HCP}}\right)$ of rock matrix cores and naturally fractured cores are $94.9 \%$ and $92.4 \%$, respectively, indicating severe damage caused by HCP. The average clay-swelling and mobilization (CSM) damage indexes $\left(D_{\mathrm{CSM}}\right)$ of rock matrix cores and naturally fractured cores are $29.6 \%$ and $38.4 \%$, respectively, indicating that the damage caused by CSM is lighter than that by HCP. HCP is the primary damage mechanism for the tight sandstone. And the damage degree of the rock matrix cores is higher than that of the naturally fractured core. The proposed procedures can be applied to identify the FFD mechanism of other tight and shale formation and provide insightful fundamental data for HFF optimization.
\end{abstract}

\section{Introduction}

The unconventional resources from an unconventional tight/shale reservoir have received significant attention in the past decades. Tight or shale gas plays have specific characteristics, such as tight reservoir rock with micro-nanodarcy permeability, high temperature (up to $200^{\circ} \mathrm{C}$ ), and highstress deviation [1-3]. During hydraulic fracturing, the viscosity of hydraulic fracturing fluid (HFF) should be carefully optimized considering the proppant carrying ability and filtrate loss control [4-6]. For conventional resources such as sandstone or carbonate formation, the viscosity of HFF should be higher to achieve the proppant carrying capacity and fluid loss control purpose. However, for the tight/shale play, the permeability of the rock matrix range is from $10^{-3}$ to $10^{-8} \mu \mathrm{m}^{2}$; the HFF could not invade to the rock matrix of the fracture surface in a deep distance due to the micrometer-to-the-nanometer pore size of tight sandstone or shale and the presence of water sensitive clay in tight or shale plays. Because the permeability of the tight reservoir is extremely low (less than $0.1 \mathrm{mD}$ ) and the pore size of tight cores is in micron or nanometer scale, tight and shale rocks usually have some clay. Clay is composed of fine slices of silicate aluminate minerals. When immersed in fracture fluid, water molecules will enter the crystal lattice of 
clay minerals, which is easy to cause volume expansion, thus blocking the pores of the fracture surface [7-10].

The fluid saturation near the fracture face zone $(1-2 \mathrm{~cm})$ may reduce gas relative permeability significantly thus impeding gas production [11]. Holditch [12] concluded that during fracturing fluid injection, when the water saturation is constant, the capillary pressure is inversely proportional to the square root of permeability, resulting in the reservoir being damaged and capillary force being increased. Therefore, the capillary force has a great influence on the reservoir recovery rate. Lan et al. [13] pointed out that the water absorption rate of shale/tight samples largely depended on the clay content, because a large amount of water in the injection fluid can be adsorbed by the clay flakes. Makhanov et al. [14] concluded that the fracturing fluid with high viscosity can only partially reduce the water absorption and the low recovery rate of water-base fracturing fluid is partly due to the spontaneous imbibition of water into the shale matrix. Therefore, the damage of fracturing fluid to the reservoir matrix should be paid more attention to and cannot be ignored. The specific permeability reduction mechanism can be as follows: (1) pore fluid is blocking due to the micro-nanopore size. A smaller pore size may cause higher capillary pressure (HCP) and increase the fluid saturation at the rock matrix near the fracture surface, thus reducing the gas relative permeability significantly and (2) pore size reduction due to the high clay content, especially for swelling clay minerals such as smectite and easy mobilization or pore blocking minerals such as illite.

For tight or shale cores, it is usually infeasible to identify which is the primary damage factor by the traditional steadystate measurement core flooding apparatus due to long measurement time (hours or even days) and the gauge accuracy (pressure gauge and flowmeter) [15]. According to experimental theory, permeability measurements in the laboratory can be divided into two categories: the steady-state method and unsteady-state method [16]. While the research on fracture fluid damage evaluation of tight reservoirs is limited and conventional evaluation methods are still widely used, core samples with 1-inch length and 2 inch-diameter are usually used to measure permeability damage in the conventional steadystate method [17]. The conventional steady-state method needs to test permeability many times under different pore pressures in order to adjust slippage effect and then get Klinkenberg permeability independent of test pressure through Klinkenberg equation matching $[16,18]$. Due to the extremely low permeability of tight core samples, conventional core permeability measurements need a long time to stabilize the flow rate and pressure, and the experimental error is largely caused by temperature changes during the experiment. Therefore, the accuracy of experimental results is affected [17, 19-21].

Brace et al. [22] proposed the pressure pulse method to solve the deficiency of conventional core permeability measurements. The pressure pulse method is different from the traditional constant pressure method and constant flow rate method, which is a transient pressure pulse method based on one-dimensional unsteady flow theory. When testing permeability, the different displacing velocity and pressure at the exit need not to be recorded, while only the attenuation of the pressure pulse needs to be recorded. This method can help in precisely controlling the flow rate and guarantee the measurement accuracy. The permeability could be calculated according to the testing results combined with the corresponding theoretical formula [23]. For tight reservoirs, it is difficult to measure the flow rate when measuring the liquid permeability of the rock sample. However, measuring the change of the pressure with time as the fluid passes through the core can be a good way to evaluate the permeability $[17,24,20]$.

In this study, the pressure transmitter was designed and developed independently for matrix damage evaluation of the low-permeability tight Tarim reservoir based on the pressure pulse method. A new method for matrix damage evaluation of the low-permeability tight reservoir called the pressure transmission method for testing low permeability was established. The primary formation damage mechanism was identified through the application of an integrated unsteady-state experimental apparatus.

\section{Methods and Procedures}

2.1. Theory and Methods. A novel unsteady-state formation damage evaluation method based on pressure transmission and pressure decay theories was used to investigate the FFD mechanism. The previous researchers well documented the pressure decay theory and pressure transmission theory as well as the experimental procedures ([25-34]). The permeability measurement theory of the pressure decay method can be described in equations (1) and (2).

Pressure difference:

$$
\Delta P_{\mathrm{D}}=\frac{P_{1}(t)^{2}-P_{2}(t)^{2}}{P_{10}{ }^{2}-P_{20}^{2}}=\frac{\Delta P(t)\left[P_{2}(t)+(1 / 2) \Delta P(t)\right]}{\Delta P_{0}\left(P_{20}+(1 / 2) \Delta P_{0}\right)} .
$$

Effective gas permeability:

$$
K=\frac{-C m_{1} \mu_{\mathrm{g}} L f_{\mathrm{z}}}{f_{1} A P_{m}\left(\left(1 / V_{1}\right)+\left(1 / V_{2}\right)\right)} .
$$

The permeability measurement theory of the pressure transmission method can be described in equation (3).

$$
\begin{gathered}
\frac{\left(P(x, t)-P_{0}\right)}{\left(P_{m}-P_{0}\right)}=\frac{1-2 \sum_{n=1}^{\infty} \operatorname{EXP}\left(\left(-\phi_{n}^{2} \eta t\right) / L^{2}\right) \sin \left(\left(x \phi_{n}\right) / L\right)}{\left(\cos \phi_{n} \sin \phi_{n}+\phi_{n}\right)} \\
\phi_{n} \tan \phi_{n}=\frac{A L \phi}{V} \\
\frac{\left(P(L, t)-P_{0}\right)}{\left(P_{m}-P_{0}\right)}=1-\operatorname{EXP}\left(\frac{-A k t}{\mu C V L}\right) \\
k=\frac{\xi \mu C_{l} V L}{(-A)}
\end{gathered}
$$

2.2. The Experimental Apparatus. The PDP200 (pressure decay method) apparatus was used to measure the degree of fracture 


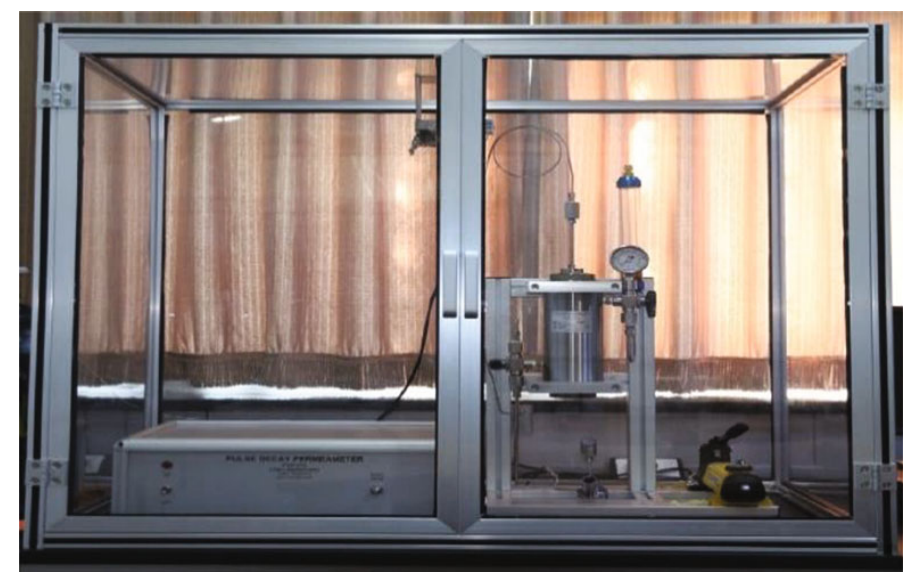

FIGURE 1: PDP200 permeability measurement apparatus (pressure decay method).

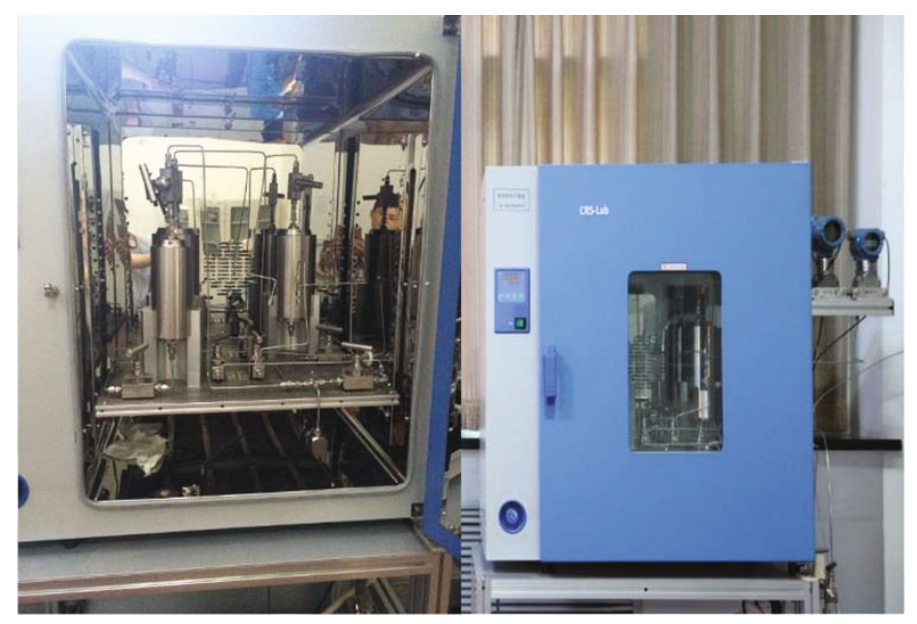

FIGURE 2: PTM permeability measurement apparatus (pressure transmission decay method).

face damage caused by HCP, while the PTM (pressure transmission method) device was used to measure the degree of fracture face damage due to CSM. Figures 1 and 2 showed the PDP200 and PTM apparatus, respectively. The PDP200 can measure the permeability in a $10^{-3}$ to $10^{-8} \mu \mathrm{m}^{2}$ range, and the PTM permeability measurement range is also from $10^{-3}$ to $10^{-8} \mu \mathrm{m}^{2}$.

2.3. Experimental Procedures. The specific procedures of the HCP damage test are shown as follows:

(1) Dry the core in the oven at $60^{\circ} \mathrm{C}$ for twenty-four hours or until the mass of the core is unchanged

(2) Measure the initial permeability $K_{\text {inil }}$ of the dried core ( 1 in diameter and 2 in length) by PDP200 apparatus

(3) Load the core in a vacuum holder for twenty-four hours or until the pressure gauge showed $-15 \mathrm{kPa}$ and is unchanged for two hours and then fill the vacuum holder with simulated formation water (the same ion type and concentration as formation water) with $2 \%$ clay-stabilizing agent for twelve hours
(4) Measure the permeability $K_{w}$ of the soaked core by the PDP200 apparatus again

(5) Calculate the HCP damage index by equation (6) as follows:

$$
D_{\mathrm{HCP}}=\frac{\operatorname{abs}\left(K_{\mathrm{w}}-K_{\text {inil }}\right)}{K_{\text {inil }}}
$$

The objective of adding a clay-stabilizing agent is to avoid the clay swelling during the measurement. The advantage of the pressure decay method is that it would not induce "fluid force" that can cause the clay mobilization. The $D_{\mathrm{HCP}}$ indicates the degree of permeability impediment by fluid saturation change or by "fluid block."

The experimental flow chart of the CSM damage test is shown in Figure 3.

The experimental procedures of the CSM damage test are shown as follows:

(1) Mix epoxy resin and hardener at 1:1 ratio by weight, pour the mixture inside a polycarbonate tubing 


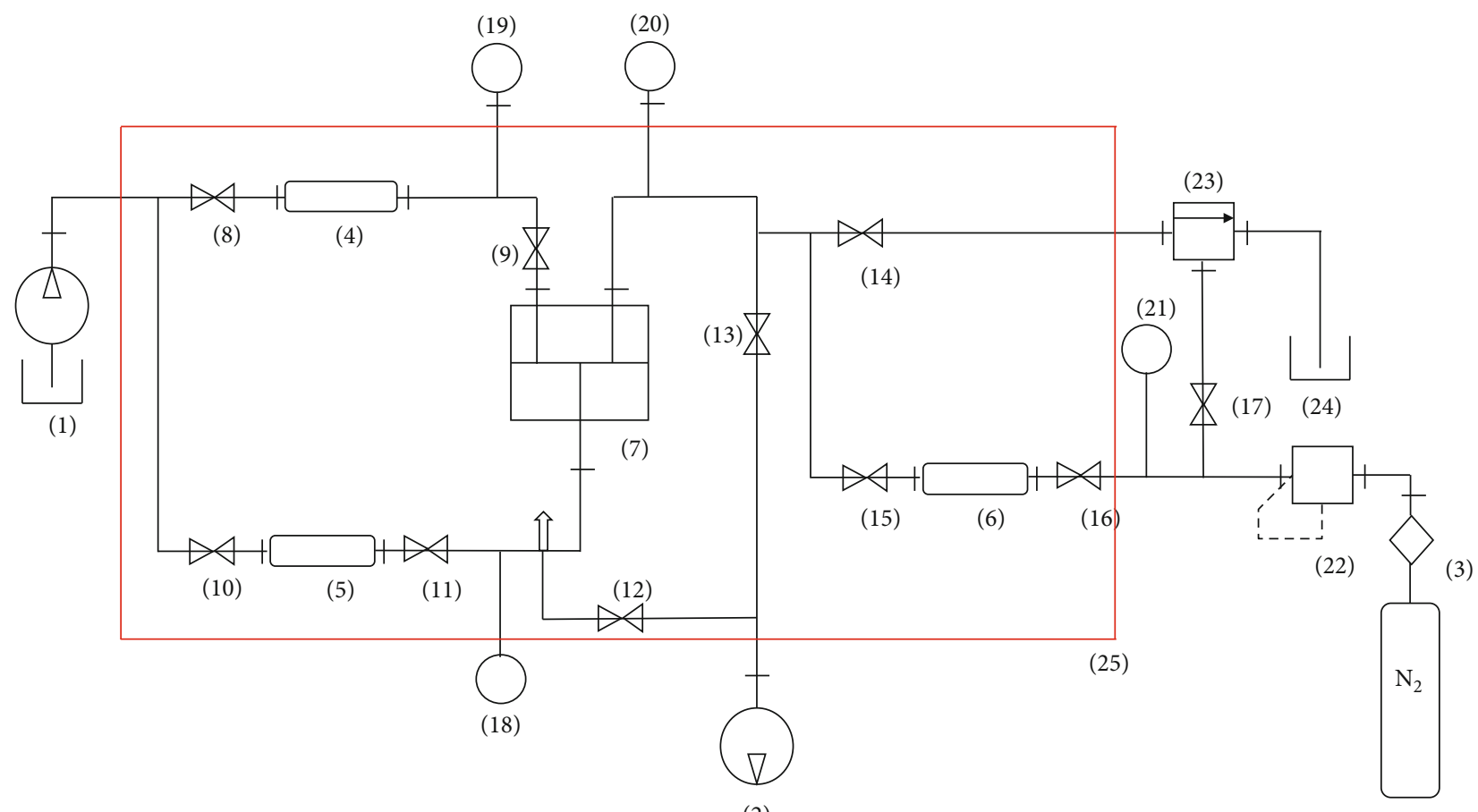

FIGURE 3: Flow chart of the pressure transmission test: (1) ISCO pump, (2) vacuum pump, (3) nitrogen gas bottle, (4) intermediate vessel for upstream and (5) downstream formation fluids, (6) intermediate container for testing fluids, (7) special core gripper, (8-17) control valve, (18-21) pressure transducer, (22) gas pressure-regulating valve, (23) back pressure valve, (24) waste liquid tank, and (25) thermotank.

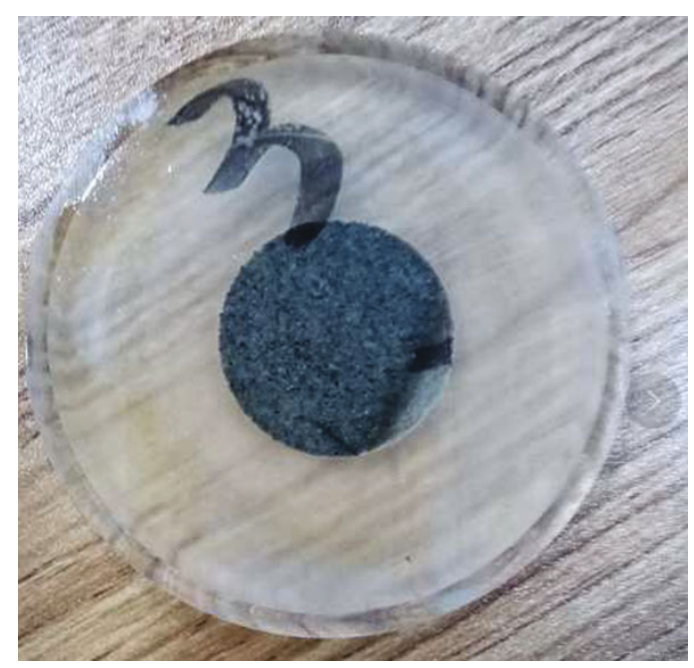

FIgURE 4: Core slice for PTM permeability measurement.

(2.5 in diameter, 4 in length), place the core in the center of the pipe, and cure for twenty hours. Slice the core in 0.25 in thickness (Figure 4), name as core slice, and load to a vacuum holder

(2) Close all control valves (8)-(17) and open valves (12) and (13) to vacuum

(3) Close control valves (8)-(17) and open valves (10) and (11). The formation water is injected into the downstream of the rock sample at the specific pressure. After the downstream pressure stabilized, it is recorded as the initial downstream pressure $P_{0}$, which should be the same as the original pore pressure of the rock sample

(4) Close control valves (8)-(17) and open ISCO pump (1), intermediate vessel (4), special core gripper (7), back pressure valve (23), gas pressure-regulating valve (22), nitrogen gas bottle (3), and valves (8), (9), (14), and (17). The formation water flows continuously on the surface of the rock sample with flow pressure $P_{\mathrm{m}}$ and back pressure $P_{\mathrm{b}}$. Continuously monitor the change of the downstream pressure $P($ $L, t)$ until it reaches the upstream flow pressure $P_{\mathrm{m}}$

(5) $P_{\mathrm{m}}, P_{0}, P(L, t)$, and equations (4) and (5) were used to obtain the liquid permeability $K_{\text {ini2 }}$ of the rock sample

(6) Close valves (8)-(17) and open special core gripper (7), intermediate vessel (6), gas pressure regulating valve (22), nitrogen gas bottle (3), and valves (15) and (16). Adjust gas pressure regulating valve (22), setup the pressure, and push the working fluid into the surface of the rock sample for approximately 5 hours

(7) Close valves (8)-(17) and repeat procedures (2)-(5). The measured liquid permeability of the damaged rock sample is $K_{\mathrm{CSM}}$

(8) The damage rate of working fluid to the core $D_{\mathrm{CSM}}$ was calculated through equation (7) as follows: 

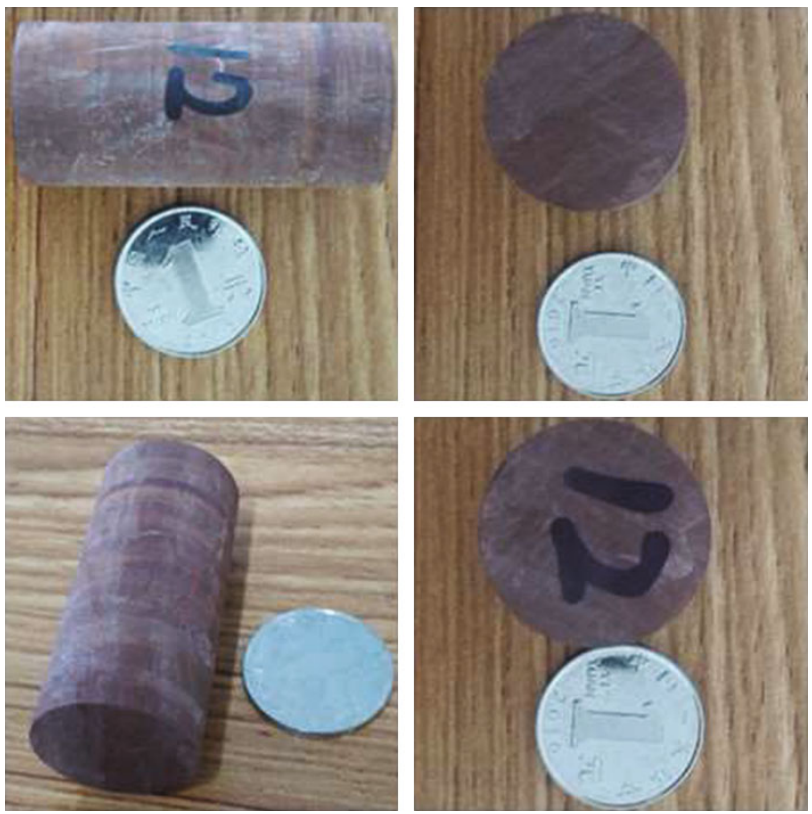

FIgURE 5: Tight sandstone core of the rock matrix.
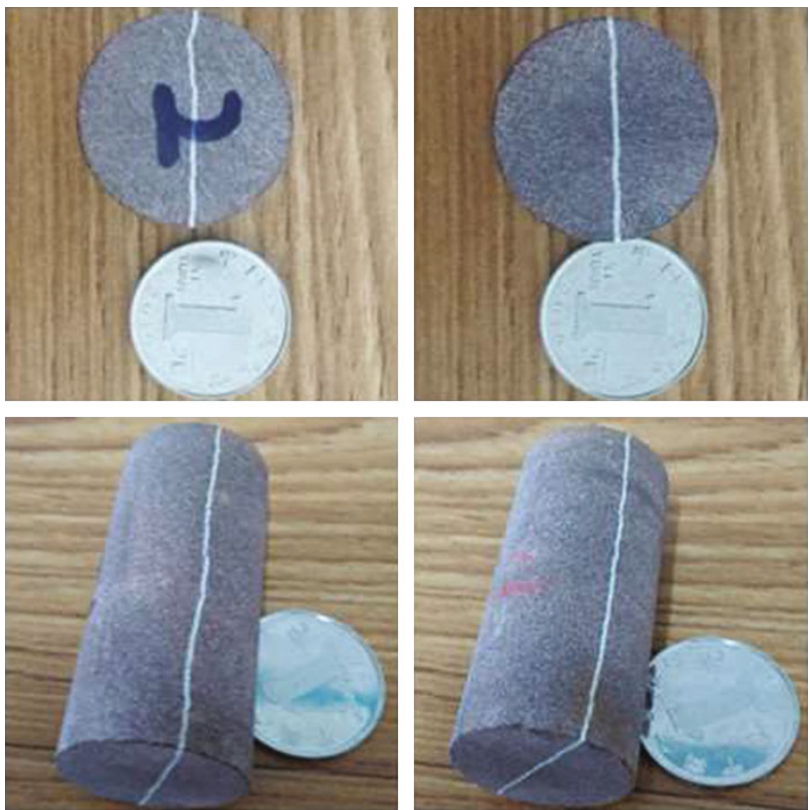

Figure 6: Tight sandstone core with a natural fracture.

$$
D_{\mathrm{CSM}}=\frac{\operatorname{abs}\left(K_{\mathrm{CSM}}-K_{\mathrm{ini} 2}\right)}{K_{\mathrm{ini} 2}}
$$

The $D_{\mathrm{CSM}}$ indicates the degree of permeability impediment by clay swelling and mobilization. Finally, by comparing the $D_{\mathrm{HCP}}$ and $D_{\mathrm{CSM}}$, the primary formation damage mechanism can be identified.

\section{Results and Discussion}

Nine tight sandstone cores of an ultradeep tight gas formation in the Tarim field (China) at a depth of around
TABle 1: Porosity and natural fracture width of the tight sandstone cores.

\begin{tabular}{lccc}
\hline Core no. & Porosity $(\%)$ & Core type & Fracture width (in) \\
\hline 1 & 2.59 & Fractured & 0.048 \\
2 & 2.32 & Fractured & 0.020 \\
4 & 2.59 & Fractured & 0.024 \\
8 & 1.47 & Fractured & 0.033 \\
12 & 0.95 & Matrix & 0.000 \\
13 & 6.09 & Fractured & 0.022 \\
14 & 1.89 & Matrix & 0.000 \\
18 & 2.47 & Fractured & 0.037 \\
20 & 2.88 & Fractured & 0.027 \\
\hline
\end{tabular}

TABLE 2: Formation water salinity test results (Tarim tight gas formation).

\begin{tabular}{lcccccc}
\hline \multicolumn{2}{c}{ Test no. } & 1 & 2 & 3 & 4 & Average \\
\hline $\mathrm{Cl}^{-}$ & $\mathrm{mg} / \mathrm{L}$ & 145000 & 146000 & 149000 & 146000 & 146500 \\
$\mathrm{SO}_{4}{ }^{2-}$ & $\mathrm{mg} / \mathrm{L}$ & 483 & 508 & 536 & 485 & 503 \\
$\mathrm{Ca}^{2+}$ & $\mathrm{mg} / \mathrm{L}$ & 13720 & 14200 & 13950 & 13370 & 13810 \\
$\mathrm{Mg}^{2+}$ & $\mathrm{mg} / \mathrm{L}$ & 814 & 752 & 742 & 897 & 801 \\
$\mathrm{~K}^{+}$ & $\mathrm{mg} / \mathrm{L}$ & 6734 & 7093 & 7459 & 4757 & 6511 \\
$\mathrm{Na}^{+}$ & $\mathrm{mg} / \mathrm{L}$ & 78130 & 78180 & 77620 & 77640 & 77893 \\
Total salinity & $\mathrm{mg} / \mathrm{L}$ & 245900 & 247800 & 250500 & 243900 & 247025 \\
\hline
\end{tabular}

TABLE 3: HCP damage test results of the tight sandstone cores.

\begin{tabular}{lccc}
\hline Core no. & $\begin{array}{c}K_{\text {ini1 }} \\
10^{-6} \mu \mathrm{m}^{2}\end{array}$ & $\begin{array}{c}K_{\mathrm{w}} \\
10^{-6} \mu \mathrm{m}^{2}\end{array}$ & $\begin{array}{c}D_{\mathrm{HCP}} \\
(\%)\end{array}$ \\
\hline 1 & 2.742 & 0.311 & 88.6 \\
2 & 4.772 & 0.227 & 95.2 \\
4 & 4.975 & 0.013 & 99.7 \\
8 & 1.665 & 0.174 & 89.6 \\
12 & 0.064 & 0.001 & 98.0 \\
13 & 69.274 & 6.893 & 90.0 \\
14 & 18.272 & 1.491 & 91.8 \\
18 & 286.049 & 33.184 & 88.4 \\
20 & 24.423 & 1.138 & 95.3 \\
\hline
\end{tabular}

$18000 \mathrm{ft}$ including two rock matrix cores and seven naturally fractured cores with different fracture widths were used for the HFF evaluation and optimization.

Figure 5 is a typical rock matrix core, and Figure 6 showed a naturally fractured core. All diameter (1 in) and length ( 2 in) of the cores were the same; Table 1 listed the detailed properties of the samples. The porosity of the cores is from $0.95 \%$ to $6.09 \%$. For the naturally fractured cores, the fracture width is ranging from 0.020 in to 0.048 in and the fractures were filled by calcite based on XRD analysis. The average formation water salinity of the Tarim tight gas formation is $247025 \mathrm{mg} / \mathrm{L}$ (Table 2), and $2 \% \mathrm{KCl}$ was also added as a clay-stabilizing agent. 


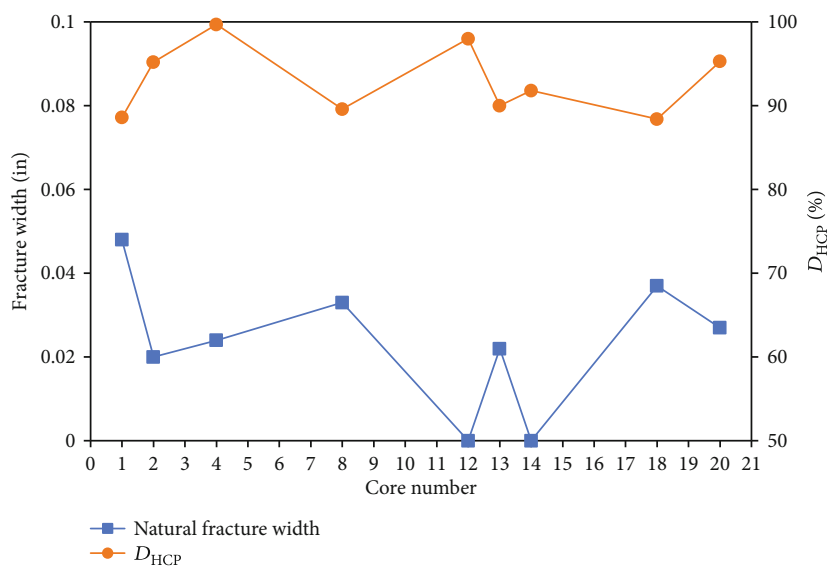

FIgURE 7: HCP damage of tight sandstone cores.

TABLE 4: XRD results of the tested tight core samples.

\begin{tabular}{|c|c|c|c|c|c|c|}
\hline Sample no. & Quartz (\%) & Feldspar (\%) & Calcite (\%) & Dolomite (\%) & Anhydrite (\%) & Clay (\%) \\
\hline 1 & 59.2 & 25.4 & 0.3 & 7.8 & 0.0 & 7.3 \\
\hline 2 & 60.9 & 23.7 & 0.0 & 7.8 & 0.8 & 6.8 \\
\hline 3 & 49.6 & 34.8 & 0.3 & 7.1 & 1.9 & 6.3 \\
\hline 4 & 53.7 & 30.3 & 0.0 & 8.5 & 0.0 & 7.5 \\
\hline 5 & 52.3 & 32.6 & 0.0 & 8.3 & 0.0 & 6.8 \\
\hline 6 & 47.0 & 34.1 & 0.0 & 9.4 & 0.7 & 8.8 \\
\hline 7 & 50.7 & 27.7 & 0.0 & 9.0 & 4.9 & 7.7 \\
\hline 8 & 51.7 & 27.1 & 0.0 & 8.3 & 5.0 & 7.9 \\
\hline 9 & 57.0 & 25.8 & 0.0 & 8.4 & 1.2 & 7.6 \\
\hline 10 & 48.0 & 32.7 & 0.0 & 9.5 & 0.9 & 8.9 \\
\hline 11 & 53.2 & 30.5 & 0.0 & 8.9 & 0.0 & 7.4 \\
\hline 12 & 54.8 & 28.3 & 0.0 & 8.0 & 1.3 & 7.6 \\
\hline 13 & 51.9 & 29.4 & 0.0 & 9.4 & 0.9 & 8.4 \\
\hline 14 & 54.5 & 28.4 & 0.0 & 8.5 & 0.0 & 8.6 \\
\hline 15 & 52.2 & 27.7 & 0.0 & 8.5 & 3.4 & 8.2 \\
\hline 16 & 54.4 & 28.8 & 0.0 & 8.2 & 0.0 & 8.6 \\
\hline 17 & 54.3 & 29.7 & 0.0 & 8.6 & 0.0 & 7.4 \\
\hline 18 & 47.7 & 34.0 & 0.0 & 10.6 & 0.0 & 7.7 \\
\hline 19 & 53.0 & 30.6 & 0.0 & 8.1 & 0.0 & 8.3 \\
\hline 20 & 41.4 & 38.7 & 0.0 & 10.2 & 1.9 & 7.8 \\
\hline
\end{tabular}

3.1. The HCP Damage Test Result. Table 3 summarized the experimental data for the $\mathrm{HCP}$ damage test. The $D_{\mathrm{HCP}}$ is from $88.4 \%$ to $99.7 \%$, indicating severe damage caused by HCP. For the naturally fractured cores, it did not show a strong correlation between the $D_{\mathrm{HCP}}$ and natural fracture width (Figure 7). The average $D_{\mathrm{HCP}}$ of rock matrix cores and naturally fractured cores are $94.9 \%$ and $92.4 \%$, respectively.

3.2. The CSM Damage Test Result. According to the XRD results, the tested tight core samples contain high content of clay minerals, between $7 \%$ and $9 \%$ (see Table 4). When immersed in water-based fracture fluid, water molecules will enter the crystal lattice of clay minerals, which easily causes volume expansion, leading to water blocking and water sensitivity. Table 5 summarized the experimental data for
TABLE 5: CSM damage test results of the tight sandstone cores.

\begin{tabular}{lccc}
\hline Core no. & $\begin{array}{c}K_{\text {ini2 }} \\
10^{-6} \mu \mathrm{m}^{2}\end{array}$ & $\begin{array}{c}K_{\mathrm{CSM}} \\
10^{-6} \mu \mathrm{m}^{2}\end{array}$ & $\begin{array}{c}D_{\mathrm{CSM}} \\
(\%)\end{array}$ \\
\hline 1 & 1.151 & 0.646 & 43.9 \\
2 & 1.938 & 1.093 & 43.6 \\
4 & 2.135 & 1.523 & 28.6 \\
8 & 0.682 & 0.406 & 40.4 \\
12 & 0.026 & 0.018 & 30.4 \\
13 & 27.676 & 17.764 & 35.8 \\
14 & 7.842 & 5.575 & 28.9 \\
18 & 114.078 & 76.489 & 33.0 \\
20 & 9.811 & 5.565 & 43.3 \\
\hline
\end{tabular}




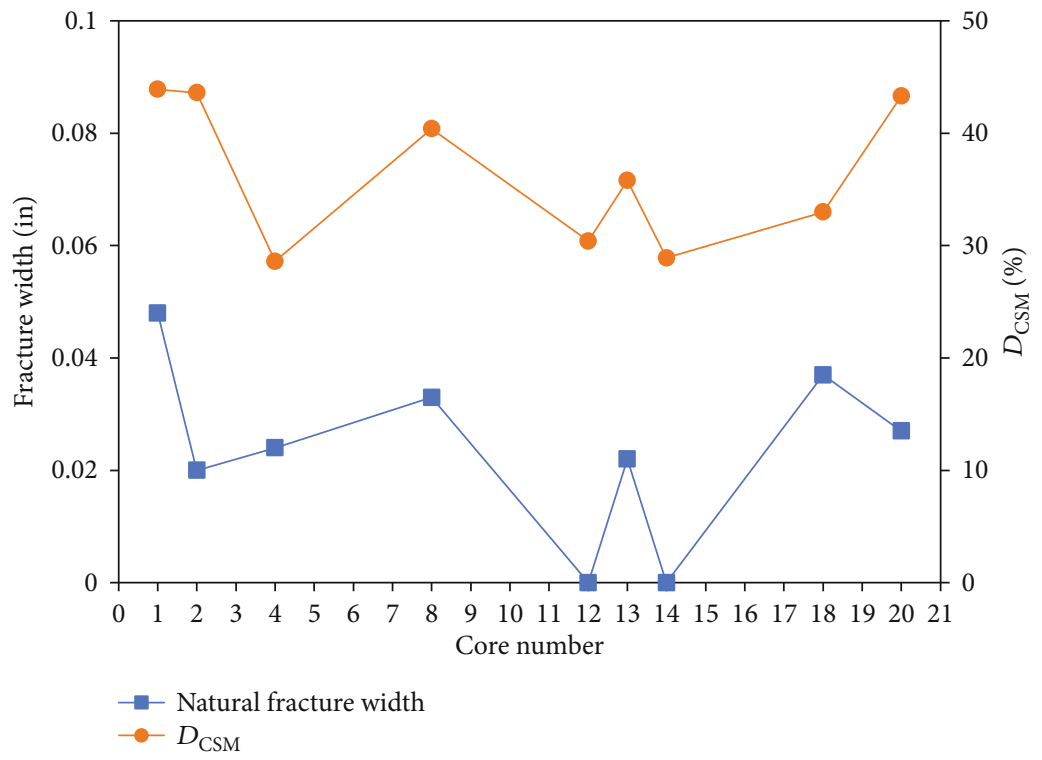

FIGURE 8: CSM damage of the tight sandstone core.
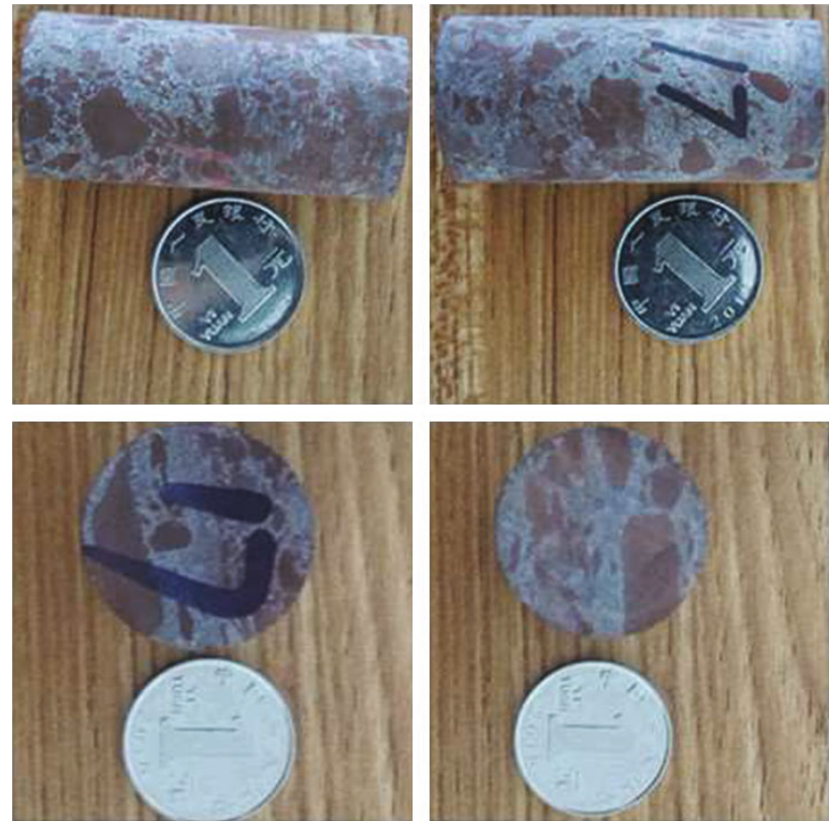

Figure 9: No. 17 tight sandstone core (rock matrix).

the CSM damage test. The $D_{\mathrm{CSM}}$ is from $28.6 \%$ to $43.9 \%$, indicating that the damage caused by CSM is lighter than that by HCP. For the naturally fractured cores, the relationship between the $D_{\mathrm{HCP}}$ and natural fracture width is also not stable (Figure 8 ). The average $D_{\mathrm{CSM}}$ of rock matrix cores and naturally fractured cores are $29.6 \%$ and $38.4 \%$, respectively.

Results showed that the $D_{\mathrm{HCP}}$ range is from $88.4 \%$ to $99.7 \%$ and the $D_{\text {CSM }}$ range is from $28.6 \%$ to $43.9 \%$. HCP damage is identified as the primary damage source of the tight gas formation. The HFF is needed to be optimized, and we modified the HFF by adding $0.5 \%$ wt anti-waterblocking agent (surfactant) to reduce the interfacial tension
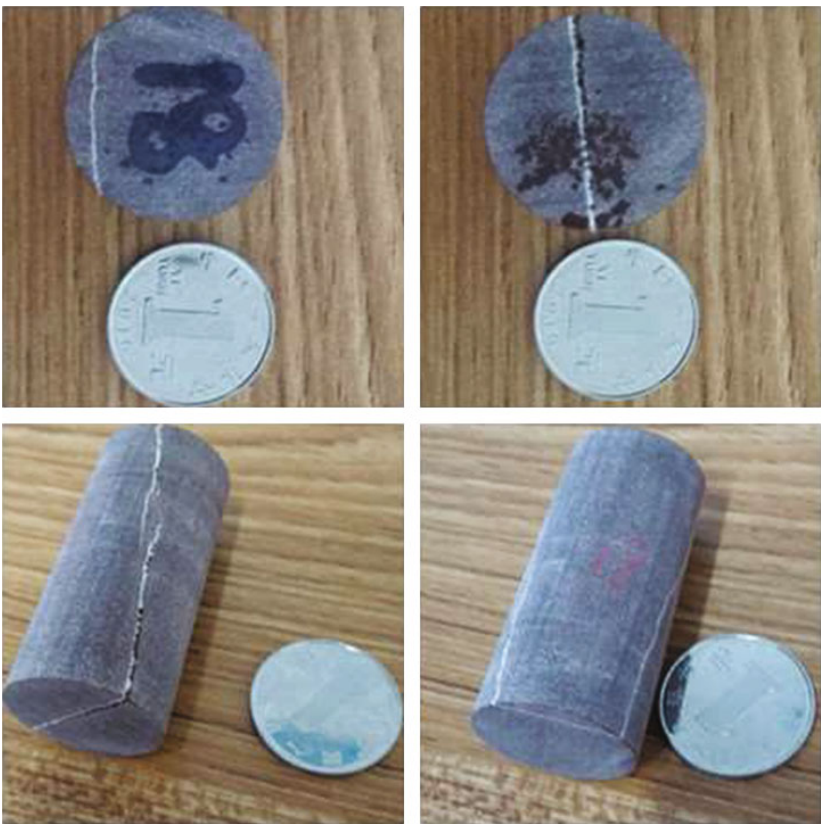

Figure 10: No. 18 tight sandstone core (naturally fractured).

of gas and water. Two cores (one rock matrix core no.17 and a naturally fractured core no.18) were used to evaluate the optimized HFF through the HCP test and CSM test at the same condition as the previous test (see Figures 9 and 10). In the HCP damage test, we also added the same $0.5 \%$ wt anti-water-blocking agent (surfactant) to the simulated formation water. Table 6 showed that the $D_{\mathrm{HCP}}$ is reduced for the two cores $(45.3 \%$ and $50.2 \%$ for the naturally fractured core and rock matrix core, respectively). The $D_{\mathrm{CSM}}$ is stabilized and within the range of the previous CSM test. The HFF can be further optimized by using more effective surfactant or increase the content of surfactant. 
Table 6: HCF and CSM Damage Test Results of the Optimized HFF.

\begin{tabular}{lcccccc}
\hline Core no. & $\begin{array}{c}K_{\text {ini1 }} \\
10^{-6} \mu \mathrm{m}^{2}\end{array}$ & $\begin{array}{c}K_{\mathrm{w}} \\
10^{-6} \mu \mathrm{m}^{2}\end{array}$ & $\begin{array}{c}D_{\mathrm{HCP}} \\
(\%)\end{array}$ & $\begin{array}{c}K_{\text {ini2 }} \\
10^{-6} \mu \mathrm{m}^{2}\end{array}$ & $\begin{array}{c}K_{\mathrm{CSM}} \\
10^{-6} \mu \mathrm{m}^{2}\end{array}$ & $\begin{array}{c}D_{\mathrm{CSM}} \\
(\%)\end{array}$ \\
\hline 17 & 20.658 & 10.288 & 50.2 & 14.325 & 10.643 & 25.7 \\
18 & 35.214 & 19.262 & 45.3 & 29.875 & 19.867 & 33.5 \\
\hline
\end{tabular}

\section{Conclusions}

In this paper, we introduce a novel experimental approach for tight gas formation damage mechanism identification. The pressure transmission method and pressure decay method were integrated to evaluate the degree of fracture face damage (FFD) caused by HCP and CSM. This method can be further applied to identify the FFD mechanism of other tight or shale formations and provide insightful fundamental data for HFF optimization. The experimental results showed the following specific conclusions:

(1) The average $D_{\mathrm{HCP}}$ of rock matrix cores and naturally fractured cores are $94.9 \%$ and $92.4 \%$, respectively, indicating severe damage caused by HCP

(2) The average $D_{\mathrm{CSM}}$ of rock matrix cores and naturally fractured cores are $29.6 \%$ and $38.4 \%$, respectively, indicating that the damage caused by CSM is lighter than that by HCP

(3) The fluid block due to HCP is the primary damage mechanism for Tarim tight sandstone. And the degree of matrix fluid block is higher than that of natural fractures

(4) After adding $0.5 \%$ wt surfactant, the $D_{\mathrm{HCP}}$ is reduced from $94.9 \%$ to $50.2 \%$ for the rock matrix, which showed the effectiveness of the proposed experimental procedures

\section{Nomenclature}

$P_{1}(\mathrm{t}): \quad$ Pressure of the upper holder $(\mathrm{MPa})$

$P_{2}(\mathrm{t}): \quad$ Pressure of the lower holder $(\mathrm{MPa})$

$\triangle P(\mathrm{t})$ : The pressure difference between the upper and the lower holders $(\mathrm{MPa})$

$C: \quad$ Unit change factor

$m_{1}$ : The slope of $\ln \left(\triangle p_{D}\right)-t$ curve

$\mu_{\mathrm{g}}: \quad$ Gas viscosity (MPa.s)

L: $\quad$ Core length $(\mathrm{cm})$

$f_{\mathrm{z}}$ : Calibration factor of gas compressibility

$f_{1}$ : Calibration factor of mass flow rate

$A$ : $\quad$ Core cross-section area $\left(\mathrm{cm}^{2}\right)$

$P_{\mathrm{m}}: \quad$ Average pore pressure $(\mathrm{MPa})$

$V_{1}$ : The volume of the upper holder $\left(\mathrm{cm}^{3}\right)$

$V_{2}$ : The volume of the lower holder $\left(\mathrm{cm}^{3}\right)$

$\eta$ : $\quad$ The rock pressure-transmitting coefficient

$\varphi: \quad$ Rock porosity (\%)

$C_{\mathrm{l}}: \quad$ Fluid compressibility (1/MPa)

$P_{0}$ : $\quad$ Initial pressure of the upper holder
$P_{m}: \quad$ Initial pressure of the lower holder

$V: \quad$ The volume of the lower holder

$\xi$ : $\quad$ The slop of $\ln \left(\left(P(L, t)-P_{0}\right) /\left(P_{m}-P_{0}\right)\right)$ and $\mathrm{t}$.

\section{Data Availability}

The data used to support the findings of this study are included within the article.

\section{Conflicts of Interest}

The authors declare that they have no conflicts of interest.

\section{Acknowledgments}

This research was supported by the National Science Foundation of China (no. 51834005), by the Innovation Fund of China National Petroleum Corporation (2019D-5007-0201), and by the Science Foundation of China University of Petroleum, Beijing (no. 2462017YJRC041). The authors appreciate the $53^{\text {rd }}$ U.S. Rock Mechanics/Geomechanics Symposium for the support to publish this paper.

\section{References}

[1] M. J. Hannon, "Fast and reliable estimates of low permeabilities by the full-immersion pressure-pulse decay," in Paper URTEC-2669302-MS presented at the SPE/AAPG/SEG Unconventional Resources Technology Conference, Austin, TX, USA, July 2017.

[2] Y. Li, M. Long, J. Tang, M. Chen, and X. Fu, "A hydraulic fracture height mathematical model considering the influence of plastic region at fracture tip," Petroleum Exploration and Development, vol. 47, no. 1, pp. 184-195, 2020.

[3] Z. W. Wu, C. Cui, G. Lv, S. Bing, and G. Cao, "A multi-linear transient pressure model for multistage fractured horizontal well in tight oil reservoirs with considering threshold pressure gradient and stress sensitivity," Journal of Petroleum Science and Engineering, vol. 172, pp. 839-854, 2019.

[4] Y. Li, M. Long, L. Zuo, W. Li, and W. Zhao, "Brittleness evaluation of coal based on statistical damage and energy evolution theory," Journal of Petroleum Science and Engineering, vol. 172, pp. 753-763, 2019.

[5] K. E. Porter, "An overview of formation damage (includes associated paper 20014)," Journal of Petroleum Technology, vol. 41, no. 8, pp. 780-786, 1989.

[6] Z. H. Zhao, K. D. Wu, Y. Fan, J. C. Guo, B. Zeng, and W. H. Yue, "An optimization model for conductivity of hydraulic fracture networks in the Longmaxi shale, Sichuan Basin, Southwest China," Energy Geoscience, vol. 1, no. 1-2, pp. 4754, 2020.

[7] L. P. Fu, K. L. Liao, J. J. Ge et al., "Study on the damage and control method of fracturing fluid to tight reservoir matrix," Journal of natural gas science and engineering, vol. 82, article ???, 2020.

[8] X. Hou, Y. Zhu, S. Chen, Y. Wang, and Y. Liu, "Investigation on pore structure and multifractal of tight sandstone reservoirs in coal bearing strata using LF-NMR measurements," Journal of Petroleum Science and Engineering, vol. 187, article 106757, 2019. 
[9] Y. Li, D. H. Zhou, W. H. Wang, T. X. Jiang, and Z. J. Xue, "Development of unconventional gas and technologies adopted in China," Energy Geoscience, vol. 1, no. 1-2, pp. 5568,2020

[10] Z. W. Wu, L. Dong, C. Cui, X. Cheng, and Z. Wang, “A numerical model for fractured horizontal well and production characteristics: comprehensive consideration of the fracturing fluid injection and flowback," Journal of Petroleum Science and Engineering, vol. 187, p. 106765, 2020.

[11] D. B. Bennion, F. B. Thomas, and T. Ma, "Formation-damage processes reducing productivity of low-permeability gas reservoirs," in Paper SPE-60325-MS presented at the SPE Rocky Mountain regional/low-permeability reservoirs symposium and exhibition, Denver, CO, USA, March 2000.

[12] S. A. Holditch, "Factors affecting water blocking and gas flow from hydraulically fractured gas wells," Journal of Petroleum Technology, vol. 31, no. 12, pp. 1515-1524, 1979.

[13] Q. Lan, E. Ghanbari, H. Dehghanpour, and R. Hawkes, "Water loss versus soaking time: spontaneous imbibition in tight rocks," Energy Technology, vol. 2, no. 12, pp. 1033-1039, 2014.

[14] K. Makhanov, A. Habibi, H. Dehghanpour, and E. Kuru, "Liquid uptake of gas shales: a workflow to estimate water loss during shut-in periods after fracturing operations," Journal of Unconventional Oil \& Gas Resources, vol. 7, pp. 22-32, 2014.

[15] N. H. G. Rahmani, J. Gao, M. N. Ibrahim, S. Bou-mikael, B. S. Al-Matar, and F. Al-Ruhaimani, "Core flood investigation into asphaltene deposition tendencies in the Marrat reservoir, South East Kuwait," in Paper SPE-121414-MS presented at the SPE International Symposium on Oilfield Chemistry, The Woodlands, The Woodlands, TX, USA, April 2009.

[16] J. C. Sun, Z. M. Yang, H. K. Guo, Q. H. Xiao, M. X. Hao, and $\mathrm{X} . \mathrm{Xu}$, "Comparative study of tight reservoir permeability using steady-state and unsteady-state methods," Rock and Soil Mechanics, vol. 34, no. 4, pp. 1009-1016, 2013.

[17] L. F. Zhang, F. J. Zhou, S. C. Zhang, J. Wang, and J. Wang, "Evaluation of drilling fluid damage to matrices of tight sandstone of Keshen gas reservoir in Tarim basin," Drilling Fluid \& Completion Fluid, vol. 36, no. 1, pp. 126-132, 2019.

[18] W. Z. Chen, J. P. Yang, G. J. Wu et al., "Experimental study on permeability in low permeability media," Chinese Journal of Rock Mechanics and Engineering, vol. 27, no. 2, pp. 236-243, 2008.

[19] Y. L. Kang, X. L. Zhang, L. J. You, and X. L. Du, “A new method to evaluate fluid sensitivity of tight reservoir: pressure decay analysis," Drilling Fluid \& Completion Fluid, vol. 30, no. 6, pp. 81-84, 2013.

[20] Y. L. Qiu, X. T. Yang, P. Guo, X. N. Niu, Z. H. Wang, and J. Y. Liu, "Evaluation experiments of basement hydrocarbon reservoir damage by mud in Dabei area, Tarim basin," Drilling \& Production Technology, vol. 37, no. 5, pp. 94-97, 2014.

[21] Z. W. Wu, C. Cui, Y. Ye, X. Cheng, and J. Trivedi, “A fractal model for quantitative evaluating the effects of spontaneous imbibition and displacement on the recovery of tight reservoirs," Journal of Petroleum Science and Engineering, vol. 198, article 108120, 2021.

[22] W. F. Brace, J. B. Walsh, and W. T. Frangos, "Permeability of granite under high pressure," Journal of Geophysical Research, vol. 73, no. 6, pp. 2225-2236, 1968.

[23] H. Y. Zhang, L. L. Liu, C. L. Liu et al., "Experimental investigation on permeability of hydrate bearing sediments based on pressure pulse method," Journal of Experimental Mechanics, vol. 33, no. 2, pp. 265-271, 2018.

[24] L. F. Zhang, F. J. Zhou, S. C. Zhang, J. Wang, M. H. Li, and J. F. Liu, "Experimental study on reservoir matrix damage caused by fracturing fluids based on transient pressure pulse method," Petroleum Geology and Recovery Efficiency, vol. 25, no. 3, pp. 89-94, 2018.

[25] K. L. Adair and N. G. Gruber, "New laboratory procedures for evaluation of drilling induced formation damage and horizontal-well performance. An update," in Paper SPE37139-MS presented at the international conference on horizontal well technology, Calgary, Alberta, Canada, November 1996.

[26] T. M. Al-Bazali, J. Zhang, M. E. Chenevert, and M. M. Sharma, "Factors controlling the membrane efficiency of shales when interacting with water-based and oil-based muds," in Paper SPE-100735-MS presented at the International Oil \& Gas Conference and Exhibition in China, Beijing, China, December 2006.

[27] J. O. Amaefule, K. Wolfe, J. D. Walls, A. O. Ajufo, and E. Peterson, "Laboratory determination of effective liquid permeability in low-quality reservoir rocks by the pulse decay technique," in Paper SPE-15149-MS presented at the SPE California Regional Meeting, Oakland, CA, USA, April 1986.

[28] T. Bourbie and J. Walls, "Pulse decay permeability: analytical solution and experimental test," Society of Petroleum Engineers Journal, vol. 22, no. 5, pp. 719-721, 1982.

[29] T. Chen and P. W. Stagg, "Semilog analysis of the pulse-decay technique of permeability measurement," Society of Petroleum Engineers Journal, vol. 24, no. 6, pp. 639-642, 1984.

[30] A. I. Dicker and R. M. Smits, "A practical approach for determining permeability from laboratory pressure-pulse decay measurements," in Paper SPE-17578-MS presented at the International Meeting on Petroleum Engineering, Tianjin, China, November 1988.

[31] S. C. Jones, "A technique for faster pulse-decay permeability measurements in tight rocks," SPE Formation Evaluation, vol. 12, no. 1, pp. 19-26, 1997.

[32] Core Laboratories, Z. Gan, T. Griffin et al., "Fast pressuredecay core permeability measurement for tight rocks," Petrophysics - The SPWLA Journal of Formation Evaluation and Reservoir Description, vol. 59, no. 5, pp. 606-616, 2018.

[33] S. Salimi and A. Ghalambor, "Experimental study of formation damage during underbalanced-drilling in naturally fractured formations," Energies, vol. 4, no. 10, pp. 1728-1747, 2011.

[34] Z. Yang, S. Bryant, and M. Dong, "A method to measure ultralow permeability of shale core in multiple directions using pressure-pulse decay technique," in Paper SPE-191511-MS presented at the SPE Annual Technical Conference and Exhibition, Dallas, TX, USA, September 2018. 